\title{
Effect of Femoral Head Diameter on Risk of Dislocation after Primary Total Hip Arthroplasty
}

Trevor H Magee ${ }^{1}$, Jordan F Schaeffer ${ }^{1}$, Daniel S Buck${ }^{1}$, Jeremy M Gililland ${ }^{\star *}$ and Aaron A Hofmann ${ }^{1}$

${ }^{1}$ Hofmann Arthritis Institute, Salt Lake City, UT 84102, USA

${ }^{2}$ University of Utah, Department of Orthopaedic Surgery, Salt Lake City, UT 84108, USA

\begin{abstract}
Dislocation is one of the most common complications of total hip arthroplasty. The diameter of the femoral head is one of the more important of the variables under the control of the surgeon. We followed 527 total hip arthroplasties in 469 patients after primary total hip arthroplasty with femoral head sizes ranging from 28 to $44 \mathrm{~mm}$. All surgeries were performed by a single surgeon at one institution. The operative approach was the posterior approach in all patients. The patients were followed at defined intervals and asked about dislocation. There was a mean follow up of 60 months with a range of 12 to 138 months. In total hip arthroplasty, utilizing the posterior approach, we found no statistically significant association between the risk of dislocation and femoral head size.
\end{abstract}

Keywords: Dislocation risk; Total hip arthroplasty; Femoral head size

\section{Introduction}

Dislocation is one of the most common complications of Total Hip Arthroplasty (THA). Historical data shows the rate of dislocation after total hip arthroplasty to be unacceptably high with an incidence of dislocation after primary THA in several large series ranging between $0.4 \%$ and $5.8 \%[1-3]$. Patient and surgical variables leading to increased risk of dislocation are neuromuscular and cognitive disorders, alcoholism, female gender, diagnosis of fracture, component malposition and patient noncompliance [4-7]. In addition to optimizing the femoral and acetabular component positioning, maximizing the diameter of the femoral head has been touted as another important intra-operative tool available to the surgeon to decrease dislocation rates. However, maximization of the femoral head size is limited and is not without consequence.

Femoral head size is determined intra-operatively by the surgeon and is dependent on the size of the acetabular component and the thickness of the liner if a modular acetabular component is utilized. If a modular acetabular component with a polyethylene liner is utilized, then there is an obvious trade off of minimization of the thickness of the polyethylene for maximization of the femoral head size. Additionally, as femoral head size increases, there is a consequent increase in volumetric wear of the bearing surface. With the advent of highly cross-linked polyethylene and the resultant decreased wear rates, there is a theoretical offset of the increased wear due to larger head sizes and this has led to more widespread use of larger femoral heads in THA.

However, despite the theoretical advantage of decreased dislocation rates with larger femoral heads, only a few studies have suggested that an increased femoral head diameter decreases the risk of dislocation [8-16], and the actual dislocation rate of larger femoral head sizes $(38-44 \mathrm{~mm})$ is largely unknown. We therefore decided to evaluate our experience with various femoral head sizes on highly cross-linked polyethylene bearings and we hypothesized that the use of larger femoral heads on highly cross-linked polyethylene would be associated with lower dislocation rates.

\section{Patients and Methods}

We retrospectively reviewed all primary total hip arthroplasties performed by a single surgeon (Aaron A. Hofmann) between January 1, 2001 and August 31, 2010. Using CPT codes and hospital records we evaluated all patients with minimum one year follow-up who were 18 years or older at the time of surgery and having had a primary THA performed by the lead surgeon Aaron A. Hofmann, MD at the University of Utah Medical Center during the aforementioned time period. Hospital records were reviewed for the patient demographic factors of age, gender and pre-operative diagnosis. Operative reports were reviewed to determine the femoral head size.

The operative approach in all patients was posterior with a capsular repair. Metal on highly cross-linked polyethylene articulations were utilized in all patients. The patients were followed at 6 weeks, 3 months, 12 months and then annually thereafter. At each visit, patients were questioned about dislocations, and any dislocation treated at our institution was identified in our chart review of emergency department records and operative reports. These THAs were then divided into two groups based on whether or not any dislocation had occurred. We then further subdivided the dislocation group into those that were stable after a single closed reduction and those that had persistent instability requiring revision. The radiographs of the dislocation group were evaluated for acetabular component malalignment based on the published Safe Zones of Lewinneck [17].

Data were analyzed by an independent statistician using commercially available software (STATA version 11, College Station, TX). Student's T-test was used for comparing all continuous variables. The chi-squared test was used to compare the binary variables if the expected frequencies were all greater than five. Fisher's exact test was used to compare those binary variables where the expected frequencies

*Corresponding author: Jeremy M. Gililland, University of Utah, Department of Orthopaedic Surgery, Salt Lake City, UT 84108 USA, Tel: 801-664-2080; Fax: 801 587-7122; E-mail: Jeremy.gililland@hsc.utah.edu

Received August 23, 2013; Accepted October 07, 2013; Published October 17 2013

Citation: Magee TH, Schaeffer JF, Buck DS, Gililland JM, Hofmann AA (2013) Effect of Femoral Head Diameter on Risk of Dislocation after Primary Total Hip Arthroplasty. J Arthritis 2: 109. doi:10.4172/2167-7921.1000109

Copyright: (c) 2013 Magee TH, et al. This is an open-access article distributed under the terms of the Creative Commons Attribution License, which permits unrestricted use, distribution, and reproduction in any medium, provided the original author and source are credited. 
were not adequate for the chi-squared test. Of the variables evaluated, gender was identified as a potential confounder as the p-value for this variable was non-significant but less than 0.25 . A linear regression controlling for this potential confounder was performed for the continuous variable of head size. Logistic regressions controlling for this potential confounder were performed for the various femoral head sizes.

\section{Results}

We identified 469 patients with a total of 527 primary THAs that met our inclusion criteria with a mean follow up of 60 months (range 12 to 138 months). These THAs had femoral head sizes ranging from $28 \mathrm{~mm}$ to $44 \mathrm{~mm}$. The femoral head diameter was $28 \mathrm{~mm}$ in 73 patients, $32 \mathrm{~mm}$ in 128 patients, $36 \mathrm{~mm}$ in 74 patients, $38 \mathrm{~mm}$ in 207 patients, and $44 \mathrm{~mm}$ in 54 patients. We identified 510 THAs in 452 patients that did not have any dislocation event and 17 patients that had at least one dislocation. This gave us an overall dislocation rate of $3.2 \%$. In the 17 dislocators the mean time to dislocation was 60 days, with a range from 3 days to 18 months. The majority of dislocations (94\%) occurred during the first 3 months after surgery. Of the dislocators, 10 (59\%) had no further dislocations after a single closed reduction, while 7 (41\%) were revised for recurrent instability.

When comparing the non-dislocators and dislocators, the groups were similar demographically in terms of age, gender and preoperative diagnosis (Table 1). The mean age of the non-dislocators was 62.2 compared to 61.9 for the dislocators $(p=0.361)$. In both groups, the majority of pre-operative diagnoses were found to be either osteoarthritis or inflammatory arthritis. While not statistically significant, we did find a trend toward a higher percentage of women in the dislocators compared to the non-dislocators $(71 \%$ vs. $52 \%$, $\mathrm{p}=0.123$ ). When comparing these two groups in terms of individual femoral head sizes and mean femoral head size, we found no difference (Table 2). Mean head size as a linear variable was found to be $36.5 \mathrm{~mm}$ in the dislocators group and $35.8 \mathrm{~mm}$ in the non-dislocator group (adjusted p-value $=0.361$ ). Additionally, when comparing the groups on head sizes by those larger than $28 \mathrm{~mm}, 32 \mathrm{~mm}, 36 \mathrm{~mm}$, and $40 \mathrm{~mm}$ respectively, we again found no difference between the groups (Table 2).

When comparing the dislocators based on whether or not revision was required for recurrent instability, the groups were found to be similar in terms of patient demographics, mean femoral head size, and number of acetabular components in the abduction safe zone, version safe zone, and both of these safe zones (Table 3). The mean acetabular

\begin{tabular}{|l|l|l|l|}
\hline & $\begin{array}{l}\text { Non-Dislocators } \\
\text { (n=452 patients) }\end{array}$ & $\begin{array}{l}\text { Dislocators (n=17 } \\
\text { patients) }\end{array}$ & p-value \\
\hline Age & 62.2 & 61.9 & 0.951 \\
\hline Gender & $\begin{array}{l}219 \mathrm{M} \mathrm{48} \% \\
233 \mathrm{~F} \mathrm{52 \%}\end{array}$ & $\begin{array}{l}5 \mathrm{M} \mathrm{29} \% \\
12 \mathrm{~F} \mathrm{71 \%}\end{array}$ & 0.123 \\
\hline Pre-Op Diagnosis & (n=510 hips) & $\mathbf{( n = 1 7}$ hips) & p-value \\
\hline Osteoarthritis & $73 \%$ & $76 \%$ & $>0.999$ \\
\hline $\begin{array}{l}\text { Inflammatory } \\
\text { Arthritis }\end{array}$ & $2 \%$ & $6 \%$ & 0.305 \\
\hline Perthes Disease & $1 \%$ & $0 \%$ & $>0.999$ \\
\hline SCFE* & $1 \%$ & $0 \%$ & $>0.999$ \\
\hline $\begin{array}{l}\text { Post-Traumatic } \\
\text { Arthritis }\end{array}$ & $7 \%$ & $0 \%$ & 0.620 \\
\hline DDH $^{*}$ & $7 \%$ & $12 \%$ & 0.326 \\
\hline AVN $^{*}$ & $9 \%$ & $6 \%$ & $>0.999$ \\
\hline
\end{tabular}

*SCFE=Slipped Capital Femoral Epiphysis, DDH=Developmental Dysplasia of the Hip, AVN=Avascular Necrosis

Table 1: Patient Demographics by Dislocation ( $n=527$ hips in 469 patients).

\begin{tabular}{|c|c|c|c|}
\hline & $\begin{array}{l}\text { Non-Dislocators } \\
\text { ( } n=510 \text { hips) }\end{array}$ & $\begin{array}{l}\text { Dislocators } \\
\text { ( } n=17 \text { hips) }\end{array}$ & p-value \\
\hline Mean Head Size & 35.8 & 36.5 & $0.361^{*}$ \\
\hline $28 \mathrm{~mm}$ Head ( $\mathrm{n}=67$ hips) & $13 \%$ & $6 \%$ & $0.416^{* *}$ \\
\hline $32 \mathrm{~mm}$ Head (n=121 hips) & $23 \%$ & $24 \%$ & $0.875^{\star *}$ \\
\hline $36 \mathrm{~mm}$ Head (n=66 hips) & $12 \%$ & $18 \%$ & $0.839^{* *}$ \\
\hline 38 mm Head (n=194 hips) & $37 \%$ & $35 \%$ & $0.847^{* *}$ \\
\hline $40 \mathrm{~mm}$ Head ( $\mathrm{n}=25$ hips) & $5 \%$ & $6 \%$ & $0.938^{* *}$ \\
\hline $42 \mathrm{~mm}$ Head (n=1 hip) & $0.2 \%$ & $0 \%$ & $>0.999^{* *}$ \\
\hline $44 \mathrm{~mm}$ Head ( $\mathrm{n}=53 \mathrm{hips})$ & $10 \%$ & $12 \%$ & $0.500^{* *}$ \\
\hline Head Size $>28 \mathrm{~mm}$ ( $\mathrm{n}=460$ hips) & $87 \%$ & $94 \%$ & $0.416^{* *}$ \\
\hline Head Size $>32 \mathrm{~mm}$ ( $\mathrm{n}=339$ hips) & $64 \%$ & $71 \%$ & $0.477^{\star *}$ \\
\hline Head Size $>36$ mm (n=273 hips) & $52 \%$ & $53 \%$ & $0.573^{* *}$ \\
\hline Head Size $>40$ mm ( $=54$ hips) & $10 \%$ & $12 \%$ & $0.938^{* *}$ \\
\hline
\end{tabular}

${ }^{*}$ A linear regression controlling for the potential confounder of gender was performed for the continuous variable of head size

${ }^{* *}$ Logistic regressions controlling for the potential confounder of gender were performed for the various femoral head sizes

Table 2: Head Size Analysis by Dislocation ( $n=527$ hips).

\begin{tabular}{|l|l|l|l|}
\hline & $\begin{array}{l}\text { Stable after Single } \\
\text { Closed Reduction } \\
\text { (n=10 hips) }\end{array}$ & $\begin{array}{l}\text { Revised for Recurrent } \\
\text { Dislocations (n=7 hips) }\end{array}$ & p-value \\
\hline Age & 61.3 & 62.9 & 0.813 \\
\hline Gender & $\begin{array}{l}4 \mathrm{M} \mathrm{40 \%} \\
6 \mathrm{~F} \mathrm{60 \%}\end{array}$ & $\begin{array}{l}1 \mathrm{M} \mathrm{14 \%} \\
6 \mathrm{~F} 86 \%\end{array}$ & 0.338 \\
\hline Osteoarthritis & $80 \%$ & $71 \%$ & $>0.999$ \\
\hline $\begin{array}{l}\text { Inflammatory } \\
\text { Arthritis }\end{array}$ & $0 \%$ & $1 \%$ & 0.412 \\
\hline Perthes Disease & $0 \%$ & $0 \%$ & $>0.999$ \\
\hline SCFE* & $0 \%$ & $0 \%$ & $>0.999$ \\
\hline $\begin{array}{l}\text { Post-Traumatic } \\
\text { Arthritis }\end{array}$ & $0 \%$ & $0 \%$ & $>0.999$ \\
\hline DDH* & $10 \%$ & $14 \%$ & $>0.999$ \\
\hline AVN* & $10 \%$ & $0 \%$ & $>0.999$ \\
\hline Mean Head Size & 36.4 & 36.6 & 0.938 \\
\hline Abduction Safe & $10 \%$ & $43 \%$ & 0.250 \\
\hline Zone & & $57 \%$ & $>0.999$ \\
\hline Version Safe Zone & $50 \%$ & $29 \%$ & 0.537 \\
\hline Both Safe Zones & $10 \%$ & $0 \mathrm{D} \%$ & \\
\hline
\end{tabular}

*SCFE=Slipped Capital Femoral Epiphysis, DDH=Developmental Dysplasia of the Hip, AVN=Avascular Necrosis

Table 3: Dislocation Sub-Analysis by need for Revision ( $n=17$ hips).

abduction angle of the dislocators was $41.94^{\circ}$ with a Standard Deviation (SD) of $\pm 8.56^{\circ}$. The mean acetabular version of the dislocators was $7.94^{\circ}$ with a standard deviation of $\pm 9.47^{\circ}$. Of those 17 THAs that dislocated, $24 \%$ were in the abduction safe zone of $30^{\circ}$ to $50^{\circ}, 53 \%$ were in the version safe zone of $5^{\circ}$ to $25^{\circ}$, and $18 \%$ were in both the abduction and version safe zones.

\section{Discussion}

Despite major advances in total hip arthroplasty, dislocation following total hip arthroplasty remains a serious complication that occurs more frequently than is desirable. Many studies have explored the factors contributing to this complication with the goal of identifying those the surgeon can control. Since the advent of highly cross-linked polyethylene bearings there has been a trend toward using larger femoral heads in total hip arthroplasty with the thought that the increased impingement free range of motion and greater amount of femoral head translation would decrease the rate of dislocation as suggested by a few studies [18-23]. We hypothesized that larger femoral head size would be associated with a decreased rate of dislocation when 
tested in vivo. Therefore the purpose of our study was to determine if femoral component head size when used with highly cross-linked polyethylene bearings had any effect on the dislocation rate of primary total hip arthroplasties.

Laboratory studies using experimental models have shown that larger femoral heads do in fact increase impingement free range of motion. These studies have also demonstrated a difference in jump distance, or translation, with the larger head sizes [24]. However none of the current studies have been done in vivo on heads greater than 32 $\mathrm{mm}$ to see if there is added benefit to using sizes larger than $32 \mathrm{~mm}$. The aforementioned laboratory data is indicative that there would be an in vivo advantage to the larger head sizes with greater Range of Motion (ROM) and joint stability. This increased ROM without componentto-component impingement will reduce the possibility of dislocation. In fact it was shown at femoral head sizes $38 \mathrm{~mm}$ and greater there is almost complete elimination of component on component impingement [24]. More precisely, once the femoral head reached $38 \mathrm{~mm}$, it was bone-on-bone impingement, which is dependent on individual bony anatomy and not related to artificial components. This translates to the ROM most closely approximating natural anatomical limits. While theoretically true there has not been consistent in vivo support of this theory, including the results of our current study.

Strengths of our study include participants selected from a single surgeon, the same hospital, equivalent post-surgical care instructions and only one surgical approach. Additionally, compared to registry and multi-center studies, we had minimum diversity between prosthetic implants. Furthermore we have evaluated dislocation in vivo, which by design includes all of the patient risk factors together, as opposed to the in vitro studies, which isolate each risk factor and ignore the synergistic effects of multiple risk factors working together. Controls in this study were all done at the same time and none of the included study participants and controls were taken from historical registries.

Limitations of this study may include possible confounders related to use of multiple implant designs that may each have differing dislocation rates due to their unique design geometry. Studies suggest that certain aspects of implant design may influence dislocation risk. Such factors include the use of skirted heads, chamfered acetabular liners, larger trunion geometry, and using a trapezoidal, rather than circular, neck cross-section [25-27]. There is also the concern that this sample size may be too small since there were only 17 dislocations to use in the calculations. With the wide variety of prosthetic devices currently in use today the results we present here will not be representative of the differences in dislocation rates due to the differing design features and the biomechanical factors specific to each of those designs. Furthermore the generalizability of the results may be questioned because the work of a single surgeon was used here whereas other studies have used multiple surgeons, which adds to the number of confounders including those due to the differences caused by individual surgical technique.

Despite the findings of the experimental models our study of in vitro total hip arthroplasties found the null hypothesis to be correct. We found no statistically significant difference in the dislocation rate between any of the patient groups. With the numbers available from this study the dislocation rate after primary THA utilizing the posterior approach with highly cross-linked polyethylene bearings is not associated with femoral head size. These findings are consistent with other clinical studies that have also shown no significant decrease in the rate of dislocation with the use of larger femoral heads $[3,4,28$ 33]. This discrepancy arises because of the multifactorial nature of dislocation. The major determinant may not be head size but some other confounding factor whose magnitude exceeds that of head size [3]. Some of these confounding factors could be component position, sources of femoral-acetabular impingement, soft-tissue tension, trauma, bearing surface wear, diagnosis or prior surgery. Within the dislocation group in this study we found only $18 \%$ of our acetabular components in the safe zone for both abduction and version, which suggests that acetabular cup malpositioning may have a greater impact on dislocation rate than the size of the femoral head component. While the data is inconsistent on the effect of femoral head size of dislocation rate, many studies have consistently shown that acetabular cup position near the "safe zone" is crucial in minimizing dislocation risk $[6,17,34,35]$. Although no studies have directly compared head size to cup position, Dudda et al. found a larger relative effect of cup malposition versus femoral head size on dislocation. Cup malposition had an odds ratio of 2.59 versus a ratio of 0.84 for a femoral head size [11].

Another question we do not address in this study is whether there is a limit to the effectiveness of larger femoral heads or some upper limit beyond which there is diminishing benefits to larger head size. One study actually indicated that there was no additional advantage after reaching a head size of $32 \mathrm{~mm}$ because it was bone on bone impingement [24]. As discussed there is greater impingement free range of motion with larger heads which decreases the incidence of levering the femoral head out of the acetabular component during normal anatomic range of motion. However there are anatomic limitations to just how much range of motion each patient can ultimately gain so at some point there will not be any additional benefit to increasing the femoral head size. The question that begs to be answered is, 'What is the upper limit of femoral head size after which no further meaningful difference is made'? In addition, data is emerging that suggests that the use of larger femoral head may lead to adverse effects and early failure [36]. Larger heads $(>36 \mathrm{~mm}$ ) may lead to increased volumetric wear and osteolysis and increased corrosion at the head-neck taper due to greater torque at the taper interface with larger femoral heads [37-40]. The increased corrosion has been linked to adverse local tissue reactions similar to those seen with a metal-on-metal bearing [41]. This new data further highlights the concern that there may be limited benefit, and risks, to using larger femoral heads.

Dislocation remains a multifactorial complication following total hip arthroplasty. While this study does not provide a concrete solution to decreasing the dislocation rate it does provide additional support to the body of evidence that head size, while important, is not the ultimate determinant of dislocation risk. It is the experience and judgment of each surgeon taking all contributing factors into consideration and reaching a decision on what is the best component combination for the patient.

\section{References}

1. Etienne A, Cupic Z, Charnley J (1978) Postoperative dislocation after Charnley low-friction arthroplasty. Clin Orthop Relat Res: 19-23.

2. Mahomed NN, Barrett JA, Katz JN, Phillips CB, Losina E, et al. (2003) Rates and outcomes of primary and revision total hip replacement in the United States medicare population. J Bone Joint Surg Am 85-85A: 27-32.

3. Woo RY, Morrey BF (1982) Dislocations after total hip arthroplasty. J Bone Joint Surg Am 64: 1295-1306.

4. Ali Khan MA, Brakenbury PH, Reynolds IS (1981) Dislocation following total hip replacement. The Journal of bone and joint surgery British volume 63-B(2): 214

5. Jolles BM, Zangger P, Leyvraz PF (2002) Factors predisposing to dislocation after primary total hip arthroplasty: a multivariate analysis. J Arthroplasty 17 282-288. 
Citation: Magee TH, Schaeffer JF, Buck DS, Gililland JM, Hofmann AA (2013) Effect of Femoral Head Diameter on Risk of Dislocation after Primary Total Hip Arthroplasty. J Arthritis 2: 109. doi:10.4172/2167-7921.1000109

6. Soong M, Rubash HE, Macaulay W (2004) Dislocation after total hip arthroplasty. J Am Acad Orthop Surg 12: 314-321.

7. Woolson ST, Rahimtoola ZO (1999) Risk factors for dislocation during the firs 3 months after primary total hip replacement. J Arthroplasty 14: 662-668.

8. Amlie $E$, Høvik $\varnothing$, Reikerås O (2010) Dislocation after total hip arthroplasty with 28 and 32-mm femoral head. J Orthop Traumatol 11: 111-115.

9. Berry DJ, von Knoch M, Schleck CD, Harmsen WS (2005) Effect of femora head diameter and operative approach on risk of dislocation after primary total hip arthroplasty. J Bone Joint Surg Am 87: 2456-2463.

10. Byström S, Espehaug B, Furnes O, Havelin LI; Norwegian Arthroplasty Register (2003) Femoral head size is a risk factor for total hip luxation: a study of 42,987 primary hip arthroplasties from the Norwegian Arthroplasty Register. Acta Orthop Scand 74: 514-524.

11. Dudda M, Gueleryuez A, Gautier E, Busato A, Roeder C (2010) Risk factors for early dislocation after total hip arthroplasty: a matched case-control study. J Orthop Surg (Hong Kong) 18: 179-183.

12. Howie DW, Holubowycz OT, Middleton R; Large Articulation Study Group (2012) Large femoral heads decrease the incidence of dislocation after total hip arthroplasty: a randomized controlled trial. J Bone Joint Surg Am 94: 1095-1102.

13. Lachiewicz PF, Soileau ES (2006) Dislocation of primary total hip arthroplasty with 36 and 40-mm femoral heads. Clin Orthop Relat Res 453: 153-155.

14. Lachiewicz PF, Soileau ES (2013) Low early and late dislocation rates with 36- and 40-mm heads in patients at high risk for dislocation. Clin Orthop Relat Res 471: 439-443.

15. Lombardi AV Jr, Skeels MD, Berend KR, Adams JB, Franchi OJ (2011) Do large heads enhance stability and restore native anatomy in primary total hip arthroplasty? Clin Orthop Relat Res 469: 1547-1553.

16. Peters CL, McPherson E, Jackson JD, Erickson JA (2007) Reduction in early dislocation rate with large-diameter femoral heads in primary total hip arthroplasty. J Arthroplasty 22: 140-144.

17. Lewinnek GE, Lewis JL, Tarr R, Compere CL, Zimmerman JR (1978) Dislocations after total hip-replacement arthroplasties. J Bone Joint Surg Am 60: $217-220$

18. Alberton GM, High WA, Morrey BF (2002) Dislocation after revision total hip arthroplasty: an analysis of risk factors and treatment options. J Bone Join Surg Am 84-84A: 1788-92.

19. Berry DJ, von Knoch M, Schleck CD, Harmsen WS (2004) The cumulative long-term risk of dislocation after primary Charnley total hip arthroplasty. J Bone Joint Surg Am 86-86A: 9-14.

20. Crowninshield RD, Maloney WJ, Wentz DH, Humphrey SM, Blanchard CR (2004) Biomechanics of large femoral heads: what they do and don't do. Clin Orthop Relat Res: 102-107

21. Hedlundh U, Ahnfelt L, Hybbinette CH, Wallinder L, Weckström J, et al. (1996) Dislocations and the femoral head size in primary total hip arthroplasty. Clin Orthop Relat Res: 226-233.

22. Kelley SS, Lachiewicz PF, Hickman JM, Paterno SM (1998) Relationship of femoral head and acetabular size to the prevalence of dislocation. Clin Orthop Relat Res: 163-170.

23. Morrey BF (1992) Instability after total hip arthroplasty. Orthop Clin North Am 23: $237-248$

24. Burroughs BR, Hallstrom B, Golladay GJ, Hoeffel D, Harris WH (2005) Range of motion and stability in total hip arthroplasty with $28-, 32-, 38-$, and $44-\mathrm{mm}$ femoral head sizes. J Arthroplasty 20: 11-19.

25. Bader R, Scholz R, Steinhauser E, Zimmermann S, Busch R, et al. (2004) The influence of head and neck geometry on stability of total hip replacement: a mechanical test study. Acta Orthop Scand 75: 415-421.

26. Barrack RL (2003) Dislocation after total hip arthroplasty: implant design and orientation. J Am Acad Orthop Surg 11: 89-99.
27. Padgett DE, Lipman J, Robie B, Nestor BJ (2006) Influence of total hip design on dislocation: a computer model and clinical analysis. Clin Orthop Relat Res 447: 48-52.

28. Dorr LD, Wolf AW, Chandler R, Conaty JP (1983) Classification and treatment of dislocations of total hip arthroplasty. Clin Orthop Relat Res: 151-158.

29. Fackler CD, Poss R (1980) Dislocation in total hip arthroplasties. Clin Orthop Relat Res: 169-178.

30. Joshi A, Lee CM, Markovic L, Vlatis G, Murphy JC (1998) Prognosis of dislocation after total hip arthroplasty. J Arthroplasty 13: 17-21.

31. Khatod M, Barber T, Paxton E, Namba R, Fithian D (2006) An analysis of the risk of hip dislocation with a contemporary total joint registry. Clin Orthop Relat Res 447: 19-23.

32. McCollum DE, Gray WJ (1990) Dislocation after total hip arthroplasty. Causes and prevention. Clin Orthop Relat Res: 159-170.

33. Ritter MA (1976) Dislocation and subluxation of the total hip replacement. Clin Orthop Relat Res: 92-94

34. Barrack RL, Lavernia C, Ries M, Thornberry R, Tozakoglou E (2001) Virtua reality computer animation of the effect of component position and design on stability after total hip arthroplasty. Orthop Clin North Am 32: 569-577, vii.

35. Biedermann R, Tonin A, Krismer M, Rachbauer F, Eibl G, et al. (2005) Reducing the risk of dislocation after total hip arthroplasty: the effect of orientation of the acetabular component. J Bone Joint Surg Br 87: 762-769.

36. Prokopetz JJ, Losina E, Bliss RL, Wright J, Baron JA, et al. (2012) Risk factors for revision of primary total hip arthroplasty: a systematic review. BMC Musculoskelet Disord 13: 251.

37. Cross MB, Nam D, Mayman DJ (2012) Ideal Femoral Head Size in Total Hip Arthroplasty Balances Stability and Volumetric Wear. HSS J 8: 270-274.

38. Dyrkacz RM, Brandt JM, Ojo OA, Turgeon TR, Wyss UP (2013) The influence of head size on corrosion and fretting behaviour at the head-neck interface of artificial hip joints. J Arthroplasty 28: 1036-1040.

39. Hammerberg EM, Wan Z, Dastane M, Dorr LD (2010) Wear and range of motion of different femoral head sizes. J Arthroplasty 25: 839-843.

40. Lachiewicz PF, Heckman DS, Soileau ES, Mangla J, Martell JM (2009) Femora head size and wear of highly cross-linked polyethylene at 5 to 8 years. Clin Orthop Relat Res 467: 3290-3296.

41. Cooper HJ, Della Valle CJ, Berger RA, Tetreault M, Paprosky WG, et al. (2012) Corrosion at the head-neck taper as a cause for adverse local tissue reactions after total hip arthroplasty. J Bone Joint Surg Am 94: 1655-1661. 